\title{
Réseau et langue de bois
}

Jean-Pierre Olivier de Sardan

\section{OpenEdition}

Journals

Édition électronique

URL : http://journals.openedition.org/apad/370

DOI : 10.4000/apad.370

ISSN : 1950-6929

Éditeur

LIT Verlag

Édition imprimée

Date de publication : 15 décembre 1991

\section{Référence électronique}

Jean-Pierre Olivier de Sardan, « Réseau et langue de bois », Bulletin de l'APAD [En ligne], 2 | 1991, mis en ligne le 30 juin 2006, consulté le 24 septembre 2020. URL : http://journals.openedition.org/apad/370 ; DOI : https://doi.org/10.4000/apad.370

Ce document a été généré automatiquement le 24 septembre 2020.

Bulletin de I'APAD 


\title{
Réseau et langue de bois
}

\author{
Jean-Pierre Olivier de Sardan
}

1 Le Bulletin de l'APAD reflète assez naturellement les difficultés ou les réussites de l'APAD. Parmi les objectifs ambitieux que nous nous sommes donnés, certains restent encore fort lointains. Il en est ainsi du dialogue entre praticiens du développement d'un côté, chercheurs en socio-anthropologie de l'autre. Ce numéro 2 du Bulletin de l'APAD témoigne d'une telle insuffisance, malgré le texte de Y. Jaffré. Il en est ainsi également des aspects méthodologiques de l'anthropologie du développement, en particulier liés à son opérationnalisation, ou, pour employer une expression à la mode, à son "appropriation" par les acteurs du développement. Dans ces deux directions voisines nous avons beaucoup de progrès à faire, et nous attendons de vous des contributions pour les numéros suivants.

2 Mais il est une fonction que l'APAD commence malgré tout tant bien que mal à remplir, et qui nous semble constituer une priorité : la fonction "réseau". C'est-à-dire permettre d'établir des liens intellectuels, professionnels et personnels entre chercheurs et praticiens, chercheurs de pays et d'institutions variés, autour d'une réflexion commune sur l'anthropologie du développement. Certes le caractère euro-africain de l'APAD n'est pas encore statistiquement établi de façon représentative, mais il y pourtant bel et bien édification d'un véritable réseau international qui est en cours. Les réunions qui ont eu lieu ou qui sont prévues à Bamako, Abidjan ou Dakar (certaines sont évoquées dans ce numéro) en sont des signes parmi d'autres. Il est clair qu'il s'agit là d'un besoin partout ressenti.

3 Paradoxalement, c'est dans les pays africains, plus encore que dans les pays européens que les chercheurs et praticiens-chercheurs nationaux ont le moins d'occasions de débattre intellectuellement autour des thèmes liés à l'anthropologie du développement, que ce soit entre eux ou que ce soit avec des chercheurs étrangers présents sur place ou de passage. Une réflexion rigoureuse autour de ce qu'on appelle parfois les "aspects sociaux ou culturels du développement" pourrait pourtant s'appuyer un peu partout sur les compétences locales, pour peu qu'une véritable vie scientifique puisse s'y développer, qui soit désenclavée et connectée aux avancées contemporaines des sciences sociales à l'échelle internationale. 
Or, la mise en place de telles dynamiques intellectuelles ne peut guère être le produit de démarches institutionnelles ou officielles. Pour créer des liens de travail et de réflexion (théorique, méthodologique, opérationnelle) qui soient transversaux, les réseaux sont plus efficaces. L'APAD doit donc, au-delà de sa forme associative, être conçue comme un réseau, et comme un appui à la constitution de réseaux.

C'est dans une telle perspective que ce numéro publie une première liste de "correspondants APAD" par pays ou par métropole, en espérant que cette initiative permettra de multiplier les contacts et de créer des synergies. Il s'agit par là d'aider à ce que, dans chaque pays, les chercheurs et les acteurs du développement intéressés par l'approche anthropologique puissent se rencontrer, débattre et, si possible, collaborer. Il s'agit aussi, ce faisant, d'aider à ce que la venue dans un pays de membres de l'APAD en mission pour une raison ou une autre puisse permettre d'organiser une réunion, une conférence, un séminaire, une prise de contact, un échange d'informations, une discussion...en Europe aussi bien qu'en Afrique. C'est, nous l'espérons, une façon d'accélérer le processus d'africanisation et d'européanisation de l'APAD.

6 Mais un réseau ne peut vivre sans contenu, sans débats. La "fonction-réseau" de l'APAD n'est pas simplement de favoriser une mise en relation, c'est aussi de favoriser une vie intellectuelle, un brassage d'idées. La rubrique "lu et à lire" doit par exemple, non seulement assurer une information sur ce qui paraît mériter d'être connu (ou critiqué!), mais aussi s'ouvrir à des divergences ou des controverses. Certains comptes-rendus d'ouvrages sont loin de susciter l'unanimité entre nous prenons chacun notre plume pour exprimer nos désaccords et les argumenter !

7 Il en est de même des autres rubriques du Bulletin : "Vie de l'APAD", "Euro-Afrique", "Agenda"...Ces rubriques doivent refléter les informations et initiative des adhérents. Il serait pour le moins paradoxal que l'APAD reproduise les travers des structures... de développement : centralisme, assistancialisme, euro-centrisme...

8 Le premier numéro, s'il a reçu en général un écho assez favorable (déjà 601 numéros diffusés...), a fait l'objet de certaines réserves ou critiques. Ce numéro; en suscitera d'autres. Il est important que réserves et critiques s'expriment par écrit dans les prochains numéros. Peut-être pourrons-nous ainsi éviter la langue de bois qui sévit autant dans les milieux de la recherche que dans ceux du développement (chacun sa langue de bois).

9 Au fait, prenons d'ores et déjà rendez-vous pour un lieu et une date où, nous l'espérons, la fonction "réseau" se manifestera et prendra un nouvel essor, et où nous l'espérons aussi, la langue de bois sera bannie : les 22, 23 et 24 octobre 1992 à Montpellier pour les journées de l'APAD. 